Structures and Buildings

Volume 171 Issue SB1

Service design approach for composite steel-concrete floors

Ranzi
Proceedings of the Institution of Civil Engineers Structures and Buildings 171 January 2018 Issue SB 1 Pages 38-49 https://doi.org/10.1680/stbu.16.00196 Paper 1600196 i

\title{
Service design approach for composite steel-concrete floors
}

Gianluca Ranzi BE, BCom, MScEng, PhD

ARC Future Fellow and Professor, School of Civil Engineering,

The University of Sydney, Sydney, NSW, Australia

(gianluca.ranzi@sydney.edu.au)

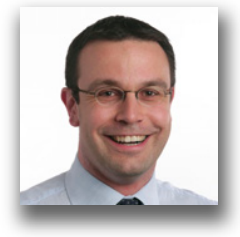

Composite steel-concrete floors are widely used throughout the world for building and bridge applications. One of their main advantages relies on using the steel sheeting as permanent formwork and, once the concrete has hardened, as external reinforcement. This form of construction finds applicability in both steel and concrete structures with the use of composite slabs and post-tensioned composite slabs, respectively. For building applications, the design of composite steel-concrete floors is usually governed by serviceability limit state requirements associated with deflections. This paper presents a new design approach for the service design of composite and post-tensioned composite slabs. The particularity of the proposed procedure relies on the ability to account for the non-uniform shrinkage profile which develops through the slab thickness when the concrete is cast on steel sheeting. This behaviour is caused by the presence of the sheeting, which prevents drying from occurring from the underside of the slab. The proposed approach is validated against experimental measurements available in the literature for full-scale long-term tests of composite slabs and post-tensioned composite slabs.

\section{Notation}

$A_{\mathrm{c}}, B_{\mathrm{c}}, I_{\mathrm{c}}$

$A_{\mathrm{g}}$

$E_{\mathrm{c}}$

$E_{\text {ef.cc }}$

$E_{\text {ef.cs }}$

$f_{\mathrm{ct}, \mathrm{f}}^{\prime}$

$f_{\mathrm{p} 1}, f_{\mathrm{p} 2}$

$I_{\text {cr }}$

$I_{\text {ef }}$

$I_{\text {ef,cc }}$

$I_{\text {ef,max }}$

$I_{\text {uncr }}$

$M_{\text {cr }}$

$M_{\mathrm{s}}$ area, first moment of area and second moment of area of the concrete component gross area of concrete component modulus of elasticity of concrete

effective modulus of concrete to be used for creep deflection

effective modulus for concrete for shrinkage calculations

characteristic flexural tensile strength of concrete

axial force and moment describing the

effects of the prestressing

second moment of area of cracked

composite slab sections

effective second moment of area of

composite section

effective second moment of area obtained

with concrete effective modulus, $E_{\text {ef,cc }}$

maximum effective second moment of area corresponding to uncracked properties second moment of area of uncracked composite slab section

cracking moment

maximum in-service moment resisted by cross-section

instantaneous distributed load

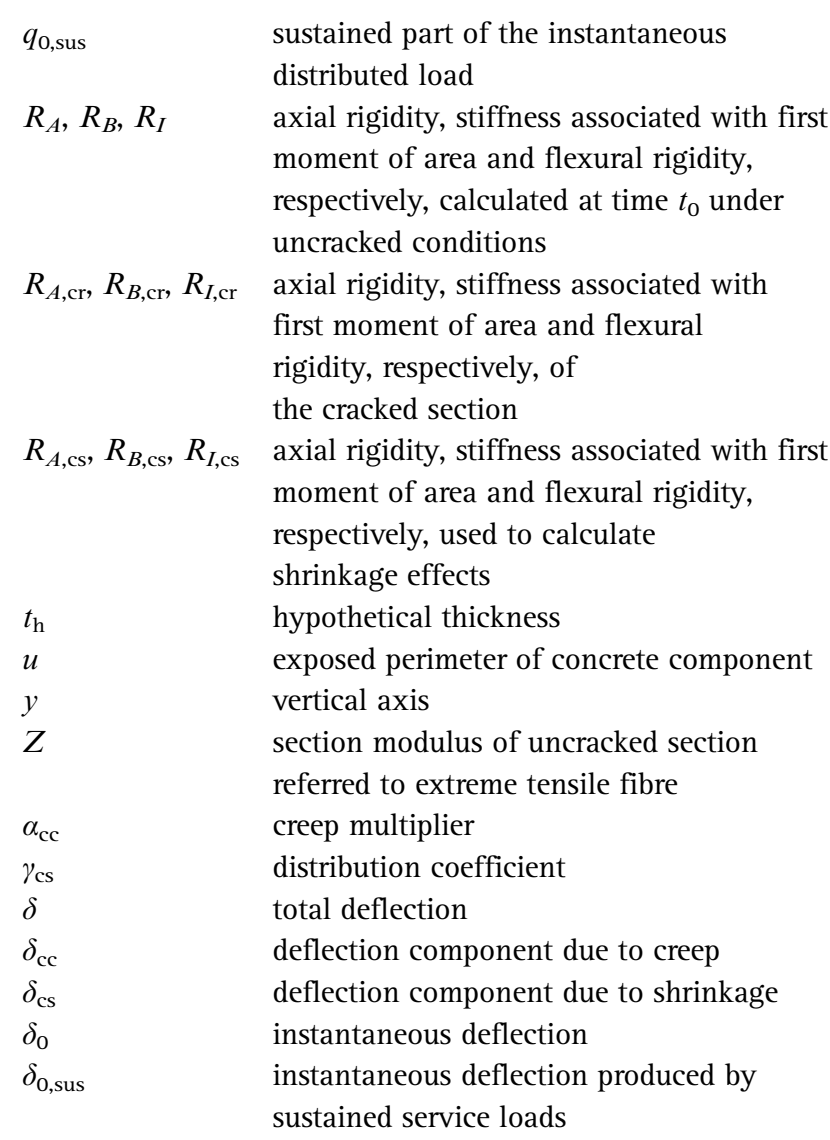

$q_{\mathrm{o} \text {,sus }}$

$R_{A}, R_{B}, R_{I}$

$R_{A, \mathrm{cr}}, R_{B, \mathrm{cr}}, R_{I, \mathrm{cr}}$

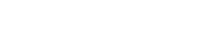$$
R_{A, \mathrm{cs}}, R_{B, \mathrm{cs}}, R_{I, \mathrm{cs}}
$$$$
t_{\mathrm{h}}
$$$$
u
$$$$
y
$$$$
\text { Z }
$$$$
\alpha_{\mathrm{cc}}
$$$$
\gamma_{\mathrm{cs}}
$$$$
\delta
$$$$
\delta_{\text {cc }}
$$$$
\delta_{\mathrm{cs}}
$$$$
\delta_{\mathrm{O}}
$$$$
\delta_{0, \text { sus }}
$$

sustained part of the instantaneous distributed load

axial rigidity, stiffness associated with first moment of area and flexural rigidity, respectively, calculated at time $t_{0}$ under uncracked conditions

axial rigidity, stiffness associated with first moment of area and flexural rigidity, respectively, of the cracked section axial rigidity, stiffness associated with first moment of area and flexural rigidity, respectively, used to calculate shrinkage effects hypothetical thickness exposed perimeter of concrete component vertical axis section modulus of uncracked section referred to extreme tensile fibre creep multiplier distribution coefficient total deflection deflection component due to creep deflection component due to shrinkage instantaneous deflection instantaneous deflection produced by sustained service loads 


\begin{tabular}{|c|c|}
\hline$\varepsilon_{\mathrm{cs}}$ & $\begin{array}{l}\text { reference shrinkage calculated in accordance } \\
\text { with reinforced concrete guidelines }\end{array}$ \\
\hline$\varepsilon_{\mathrm{cs}, \mathrm{r}}$ & $\begin{array}{l}\text { shrinkage strain at level of arbitrary } \\
\text { reference axis }\end{array}$ \\
\hline$\varepsilon_{\mathrm{p}, \text { init }}$ & $\begin{array}{l}\text { strain produced in a strand during initial } \\
\text { prestressing }\end{array}$ \\
\hline$\kappa_{\mathrm{a}, 0}, \kappa_{\mathrm{b}, 0}, \kappa_{\mathrm{c}, 0}$ & $\begin{array}{l}\text { curvatures at the two ends and at mid-span } \\
\text { of the slab segment }\end{array}$ \\
\hline$\kappa_{\mathrm{cs}}$ & shrinkage-induced curvature \\
\hline$\kappa_{\mathrm{cs}, \mathrm{cr}}$ & $\begin{array}{l}\text { curvature induced by shrinkage considering } \\
\text { the cracked properties of the composite slab }\end{array}$ \\
\hline$\kappa_{\mathrm{cs}, \mathrm{r}}$ & shrinkage curvature \\
\hline$\kappa_{\mathrm{cs}, \text { uncr }}$ & $\begin{array}{l}\text { curvature induced by shrinkage considering } \\
\text { the uncracked properties of the composite } \\
\text { slab }\end{array}$ \\
\hline$\sigma_{\text {cpre }}$ & $\begin{array}{l}\text { compressive stress induced by post- } \\
\text { tensioning at the extreme tensile fibre while } \\
\text { accounting for all prestressing losses } \\
\text { at time of interest }\end{array}$ \\
\hline$\sigma_{\mathrm{cs}}$ & $\begin{array}{l}\text { maximum shrinkage-induced tensile stress } \\
\text { at extreme fibre of uncracked section }\end{array}$ \\
\hline$\phi_{\mathrm{cc}}$ & $\begin{array}{l}\text { concrete creep coefficient calculated at } \\
\text { time } t \text { for a load first applied at } t_{0}\end{array}$ \\
\hline$\phi_{\mathrm{p}}$ & creep coefficient for the prestressing steel \\
\hline
\end{tabular}

\section{Introduction}

Composite steel-concrete structures are widely used throughout the world for building and bridge applications because they provide economical and efficient structural solutions. This form of construction combines the advantages of two composite flooring systems, namely, composite slabs (Figure 1(a)) in steel structures and post-tensioned slabs (Figure 1(b)) in concrete structures. These flooring systems include thin-walled profiled steel sheeting, non-prestressed reinforcement, concrete and prestressing strands in post-tensioned slabs. The main advantage of composite slabs relies on the ability of the profiled steel sheeting to act as permanent formwork and, once the concrete has hardened, as external reinforcement. Unlike the case of steel reinforcing bars, which are cast in the concrete, the sheeting does not benefit from being totally embedded in the concrete and the composite response depends on the interface behaviour between the profiled steel sheeting and the concrete slab. The magnitude of this resistance can be modified by manufacturers varying the geometry of the steel profiles and the indentations or protrusions specified on the sheeting.

The design of composite floor systems is carried out by satisfying a number of limit states. For building applications, serviceability limit state requirements associated with deflections tend to control the floor slab design (e.g. Ranzi et al., 2013a). Available international guidelines differ in the requirements specified to comply with serviceability limit state

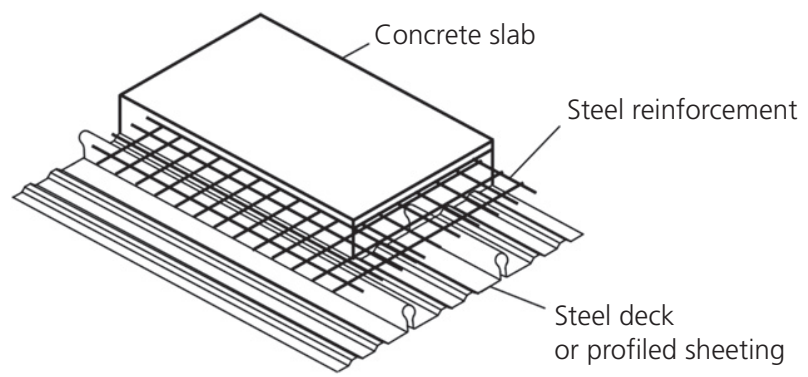

(a)

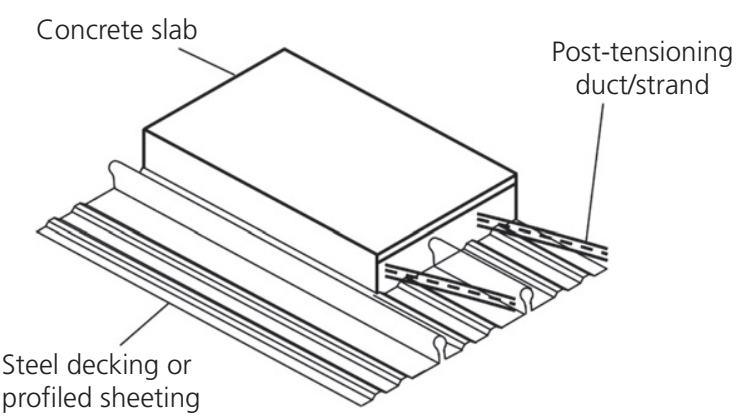

(b)

Figure 1. Typical composite steel-concrete floors: (a) composite slab; (b) post-tensioned composite slab

conditions. For example, within specified ranges of spanto-depth ratios and for ductile profiled sheeting, some design specifications allow deflection checks to be omitted in the service design (e.g. BS EN 1994-1-1 (BSI, 2005)). In other instances, engineers have relied on concrete codes (e.g. BS EN 1992-1-1 (BSI, 2004); AS 3600 (SA, 2009)) for the definition of the time-dependent properties of the concrete and, in particular, of the shrinkage characteristics, and have calculated the shrinkage strain to be used in the design assuming a hypothetical thickness $t_{\mathrm{h}}$ equal to about twice the slab thickness (i.e. equal to $t_{\mathrm{h}}=2 A_{\mathrm{g}} / u$, where $A_{\mathrm{g}}$ represents the gross area of the concrete component and $u$ depicts the exposed perimeter). The calculated shrinkage was then assumed to remain constant over the slab thickness for the service analysis and calculations.

In this context, the present paper presents a new design model for serviceability limit state that places particular attention on the effects produced by concrete shrinkage. This model reflects recent experimental measurements obtained from long-term tests that highlighted the occurrence of a shrinkage gradient over the thickness of composite slabs and post-tensioned composite slab samples. The gradient is produced by the presence of the profiled sheeting that prevents moisture from egressing from the underside of the slab.

In the first part of the paper, the main aspects related to the time-dependent behaviour of the concrete used in composite 
floor systems are introduced, highlighting the occurrence of non-uniform shrinkage profiles. The design model is then proposed in the second part of the paper, followed by its validation against long-term experimental test results available in the literature for both composite slabs (Gholamhoseini, 2014; Gholamhoseini et al., 2014) and post-tensioned composite slabs (Ranzi et al., 2012, 2013b). Expressions used in the validation process have also been provided because they are useful for design calculations.

\section{Time-dependent properties of concrete relevant to composite slab applications}

The time-dependent behaviour of concrete, characterised by creep and shrinkage, produces variations in deformations and stresses over time. In particular, when concrete is subjected to a sustained stress it undergoes deformations which increase with time and this behaviour is usually referred to as creep. Shrinkage is a stress-independent effect and leads to significant volume changes which, if restrained, can induce the development of internal stresses and the possible occurrence of cracking (e.g. Gilbert and Ranzi, 2011).

When dealing with composite floor systems, recent work has shown that a shrinkage gradient develops through the depth of the slab because of the inability of moisture to egress from the underside of the slab due to the presence of the steel sheeting. This was first observed experimentally in long-term tests carried out on composite steel-concrete beams with composite slabs (Al-Deen et al., 2011). Subsequent work focused on the time-dependent response of composite slabs and posttensioned composite slabs (e.g. Al-Deen et al., 2015; Gholamhoseini et al., 2014; Ranzi et al., 2013b; Shayan et al., 2010). Theoretical models have also been proposed in the last few years to capture the effects of the shrinkage gradient on the overall structural response (e.g. Al-Deen and Ranzi, 2015; Bradford, 2010; Gilbert et al., 2012; Ranzi and Vrcelj, 2009; Ranzi et al., 2013b).

The development of the shrinkage gradient has been investigated in isolated unreinforced concrete samples by measuring total deformations taking place over time through the thickness of the slab (e.g. Al-Deen et al., 2011; Gilbert et al., 2012; Ranzi et al., 2013b). These specimens had a square shape in plan, with edges varying between about $500 \mathrm{~mm}$ and $1000 \mathrm{~mm}$, and thicknesses in the range of $120-300 \mathrm{~mm}$. In this work, companion samples with different exposure conditions were prepared and monitored, that is, with one exposure condition allowing the concrete to dry from both sides of the slab sample (Figure 2(a)) and a second exposure condition exposing only one side for drying and sealing the opposite slab surface (Figure 3(a)). Qualitative representations of the total deformations recorded during these tests for the two exposure conditions are outlined in Figures 2(b) and 3(b). In particular, Figure 2(b) depicts constant deformations taking place through a slab exposed on both sides and varying

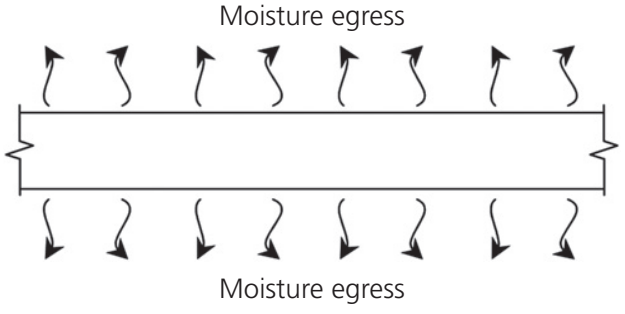

(a)

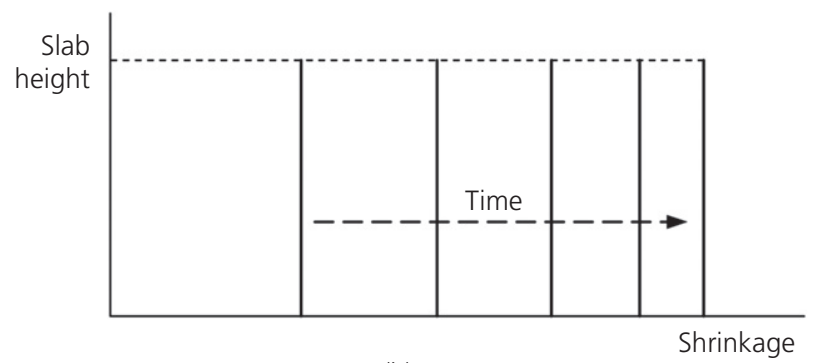

(b)

Figure 2. Typical concrete slab exposed on both sides: (a) drying condition; (b) qualitative shrinkage distribution (plotted assuming a linear shrinkage profile)

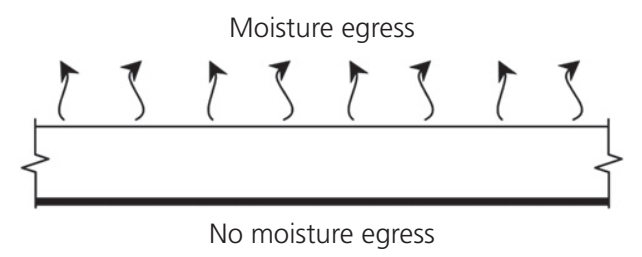

(a)

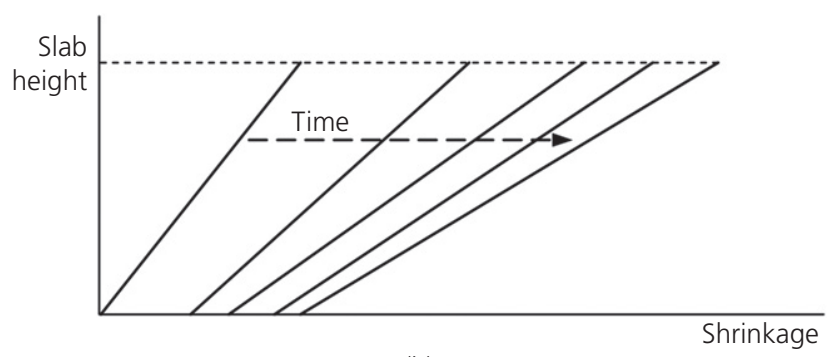

(b)

Figure 3. Typical concrete slab exposed on one side only: (a) drying condition; (b) qualitative shrinkage distribution (plotted assuming a linear shrinkage profile)

over time. Under the simplifying assumptions of linear shrinkage profiles (commonly adopted for reinforced concrete design), the total deformations depicted in Figure 2(b) can be assumed to represent the shrinkage deformations. In reality, the shrinkage distribution is non-uniform and produces self-equilibrating stresses (e.g. Gilbert and Ranzi, 2011). In the case of a slab exposed on one side only (Figure 3), a strain 
gradient develops through the cross-section over time. Relying on the simplifying assumption of linear shrinkage distributions (which are acceptable for design purposes), it is possible to assume that the measured total deformations correspond to the shrinkage profile. Also in this case, the real shrinkage distribution is more complex. Obviously, higherorder polynomials, or other functions, could be considered for refined service calculations, whereas it is assumed that a linear shrinkage distribution is sufficient for routine design purposes.

\section{Design model for serviceability limit state}

The design approach presented in this paper predicts the total deflection of a composite slab $\delta$ as the sum of the deflection components associated with the instantaneous deflection $\delta_{0}$ and those produced by creep $\left(\delta_{\mathrm{cc}}\right)$ and shrinkage $\left(\delta_{\mathrm{cs}}\right)$ effects

1. $\delta=\delta_{0}+\delta_{\mathrm{cc}}+\delta_{\mathrm{cs}}$

The proposed procedure is applicable for composite slabs whose partial interaction does not influence the service behaviour. This condition is verified for each profiled sheeting by performing experimental tests (e.g. reference should be made to AS 2327 (SA, 2017) for details of a possible testing protocol), as it is usually the case for the characterisation of the composite action properties exhibited by a steel sheeting profile (e.g. BS EN 1994-1-1 (BSI, 2005); AS 2327 (SA, 2017))

The instantaneous deformations are calculated following a procedure commonly applied to reinforced concrete slabs based on which short-term flexural deflection $\delta_{0}$ is determined at the time of first loading $t_{0}$ by means of the effective flexural rigidity $E_{\mathrm{c}} I_{\mathrm{ef}}$, where $E_{\mathrm{c}}$ represents the modulus of elasticity of the concrete and $I_{\mathrm{ef}}$ depicts the effective second moment of area of the cross-section. In the calculations presented in the paper, the expression specified in the references (e.g. AS 3600 (SA, 2009); AS 2327 (SA, 2017)) for the evaluation of $I_{\text {ef }}$ is adopted and defined as

2. $I_{\mathrm{ef}}=I_{\mathrm{cr}}+\left(I_{\mathrm{uncr}}-I_{\mathrm{cr}}\right)\left(\frac{M_{\mathrm{cr}}}{M_{\mathrm{s}}}\right)^{3} \leq I_{\mathrm{ef}, \text { max }}$

in which $I_{\text {uncr }}$ and $I_{\text {cr }}$ are the second moment of area of the uncracked and cracked composite slab sections, respectively, with the steel reinforcement and steel sheeting transformed to an equivalent area of concrete; $M_{\mathrm{s}}$ is the maximum in-service moment resisted by the cross-section; $I_{\text {ef, max }}$ depicts the maximum effective second moment of area corresponding to the uncracked properties; and $M_{\mathrm{cr}}$ denotes the cracking moment and is determined as

3. $M_{\mathrm{cr}}=Z\left(f_{\mathrm{ct}, \mathrm{f}}^{\prime}-\sigma_{\mathrm{cs}}+\sigma_{\mathrm{cpre}}\right) \geq 0$

where $f_{\mathrm{ct}, \mathrm{f}}^{\prime}$ defines the characteristic flexural tensile strength of concrete; $Z$ is the section modulus of the uncracked section referred to the extreme tensile fibre; $\sigma_{\text {cpre }}$ is the compressive stress induced by the post-tensioning at the extreme tensile fibre while accounting for all prestressing losses; and $\sigma_{\mathrm{cs}}$ is the maximum shrinkage-induced tensile stress at the extreme fibre of the uncracked section. The concrete properties and the prestress losses of the strands are determined at the time of interest.

When evaluating the instantaneous deflections, the effective flexural rigidity $E_{\mathrm{c}} I_{\mathrm{ef}}$ to be used in the member analysis depends on the static configuration of the composite slabs. In particular, for a simply-supported member, the effective flexural rigidity is evaluated based on the effective moment of area $I_{\mathrm{ef}}$ calculated at mid-span using Equation 2. In the case of continuous members, the effective flexural rigidity is calculated considering a weighted value of the effective moments of area $I_{\text {ef }}$ calculated for the cross-sections located at mid-span and at the spans' ends (i.e. for an interior span weights adopted for $I_{\mathrm{ef}}$ are 0.5 and 0.25 for the mid-span and end spans, respectively, and for an end span these weights become 0.5 at both mid-span and the continuous end while no account is made for the end support).

The creep deflection component $\delta_{\mathrm{cc}}$ is determined based on the effective modulus method (e.g. Gilbert and Ranzi, 2011). With this approach, the creep deformations are calculated considering the sustained part of the instantaneous load initially applied at time $t_{0}$. In the case of propped construction, the sustained components of the load are usually produced by the self-weight of the slab and by the long-term component of the live or variable load (i.e. the part of the live or variable load that is assumed to remain sustained), while, for unpropped construction, the sustained load is usually represented by the long-term live or variable load component as the self-weight of the slab is assumed to be carried by the profiled sheeting. The instantaneous deflection produced by the sustained service load is denoted as $\delta_{0 \text {.sus }}$ (to differentiate it from the instantaneous deflection component $\delta_{0}$ that is usually determined considering a larger level of load (e.g. BS EN 1990 (BSI, 2002); AS/NZS 1170·0:2002 - SA, 2002)) based on which the creep deflection component $\delta_{\mathrm{cc}}$ becomes

4a. $\quad \delta_{\mathrm{cc}}=\delta_{0, \mathrm{sus}} \alpha_{\mathrm{cc}}$

and

4b. $\quad \alpha_{\mathrm{cc}}=\frac{E_{\mathrm{c}} I_{\mathrm{ef}}}{E_{\mathrm{ef}, \mathrm{cc}} I_{\mathrm{ef}, \mathrm{cc}}}-1$ 
where $E_{\text {ef,cc }}\left(=E_{\mathrm{c}} /\left(1+\phi_{\mathrm{cc}}\right)\right)$ is the effective modulus of the concrete to be used for the creep deflection; $I_{\mathrm{ef}, \mathrm{cc}}$ depicts the effective second moment of area obtained using the format of Equation 2 with the concrete effective modulus $E_{\text {ef,cc }}$; and $\phi_{\mathrm{cc}}$ is the concrete creep coefficient calculated at the time of interest $t$ for a load first applied at $t_{0}$ and is determined based on concrete guidelines (e.g. BS EN 1992-1-1 (BSI, 2004); AS3600 (SA, 2009)) considering a hypothetical thickness $t_{\mathrm{h}}=2 A_{\mathrm{g}} / u$ with $A_{\mathrm{g}}$ equal to the composite slab cross-sectional area and $u$ being its exposed perimeter. This representation is assumed to be acceptable for design purposes and further refinements of the model should aim at establishing a creep representation that accounts for the inability of the composite slab to dry from its underside. In the evaluation of $I_{\text {ef,cc}}$, it is assumed that the cracked cross-section (i.e., the area of concrete cracked) corresponds to the one identified at time $t_{0}$ for the instantaneous calculations.

The deflection component due to shrinkage $\delta_{\mathrm{cs}}$ is obtained considering the effects produced by the following shrinkageinduced curvature $\kappa_{\mathrm{cs}}$ along the composite member

5a. $\quad \kappa_{\mathrm{cs}}=\left(1-\gamma_{\mathrm{cs}}\right) \kappa_{\mathrm{cs}, \mathrm{cr}}+\gamma_{\mathrm{cs}} \kappa_{\mathrm{cs}, \text { uncr }}$

and

5b. $\quad \gamma_{\mathrm{cs}}=\left(\frac{M_{\mathrm{cr}}}{M_{\mathrm{s}}}\right)^{2} \leq 1$

where $\kappa_{\mathrm{cs}, \text { uncr }}$ and $\kappa_{\mathrm{cs}, \mathrm{cr}}$ represent the curvatures induced by shrinkage over the uncracked and cracked properties of the composite slab, respectively, determined with the effective modulus for the concrete $E_{\mathrm{ef}, \mathrm{cs}}\left(=E_{\mathrm{c}} /\left(1+0 \cdot 55 \phi_{\mathrm{cc}}\right)\right)$.

For design purposes, the shrinkage gradient to be used for routine design can be expressed (under the simplifying assumptions of a linear shrinkage profile as discussed in the previous section) as a function of a reference shrinkage $\varepsilon_{\mathrm{cs}}$ calculated in accordance with reinforced concrete guidelines (e.g. EN 19921-1 (CEN, 2004a); AS 3600 (SA, 2009)), considering a hypothetical thickness equal to the thickness of the composite slab and assuming both sides of the slab to be exposed. The shrinkage gradient is then assumed, for the purpose of the design model, to vary from a value of $0 \cdot 2 \varepsilon_{\mathrm{cs}}$ at the base of the slab to $1 \cdot 2 \varepsilon_{\mathrm{cs}}$ at the top surface of the slab. The selection of the reference strain $\varepsilon_{\mathrm{cs}}$ is a consequence of the fact that the top and bottom values of the non-uniform shrinkage profile have been calibrated experimentally against those exhibited by companion concrete slab samples exposed on both sides, with the same thickness as the composite specimens (e.g. Al-Deen and Ranzi, 2015; Al-Deen et al., 2011). The adopted shrinkage distribution (i.e. use of $0 \cdot 2 \varepsilon_{\mathrm{cs}}$ and $1 \cdot 2 \varepsilon_{\mathrm{cs}}$ to define the shrinkage profile) is a simplification of the real shrinkage behaviour that takes place in the slab over time. For a general profiled steel sheeting, it is felt that the proposed approach should be favoured over the use of a uniform shrinkage distribution for the evaluation of the shrinkage deflection component. More refined representations could be obtained for the shrinkage distribution, for example, separating the effects of the autogenous shrinkage (not influenced by the surface drying conditions) and the drying shrinkage component. These refined predictions could also rely on advanced hydro-thermo-chemical-mechanical models for the concrete to better capture the shrinkage profile variations over time and considering the influence of different steel sheeting profiles.

It is worth mentioning that the use of surface treatments or the installation of floor coverings can influence and reduce the ability of a composite slab to dry from its upper face, and therefore influence the shrinkage profile produced during the drying process. It is suggested to account for this effect only for the duration of time over which the designer is certain that the surface treatments or coverings will be effective and will be reducing the drying of the upper surface of the composite slab.

\section{Expressions for routine design}

This section presents useful design expressions for the deflection predictions that can be used for determinate structural systems. For indeterminate structural systems, the redistribution of internal actions taking place over time and how these are influenced by concrete cracking need to be accounted for in the deflection calculations.

When considering a simply-supported slab of length $L$ subjected to a uniformly distributed load $q_{0}$, the instantaneous deflection $\delta_{0}$ can be determined under the assumptions of an Euler-Bernoulli beam model based on the well-known expression (Ranzi and Gilbert, 2015)

$$
\text { 6. } \delta_{0}=\frac{5}{384} \frac{q_{0} L^{4}}{E_{\mathrm{c}} I_{\mathrm{ef}}}
$$

where the instantaneous flexural rigidity $E_{\mathrm{c}} I_{\mathrm{ef}}$ is calculated based on the properties of the mid-span cross-section based on Equation 2. In the deflection calculations for the prestressed composite slabs, the effect of the prestressing can be considered by the inclusion of equivalent distributed loads based on parabolic prestressing layouts (e.g. Gilbert et al., 2017). In other structural arrangements, adjacent spans and overhangs might influence the structural response and, in these cases, the midspan deflections are estimated based on the curvature values determined at the slab segment ends and at mid-span (e.g. Ranzi and Gilbert, 2015)

7. $\delta_{0}=\frac{L^{2}}{96}\left(\kappa_{\mathrm{a}, 0}+10 \kappa_{\mathrm{c}, 0}+\kappa_{\mathrm{b}, 0}\right)$ 
where $\kappa_{\mathrm{a}, 0}, \kappa_{\mathrm{b}, 0}$ and $\kappa_{\mathrm{c}, 0}$ are the curvatures calculated from cross-sectional analyses carried out at the two ends and at mid-span of the slab segment of length $L$, respectively.

The cracking moment $M_{\mathrm{cr}}$ of Equation 3 can be re-written based on the properties of a particular section as follows

$8 a$.

$$
\begin{aligned}
M_{\mathrm{cr}}= & \frac{1}{E_{\mathrm{c}}\left[R_{B} / R_{0}-y\left(R_{A} / R_{0}\right)\right]}\left[\left(f_{\mathrm{ct}, \mathrm{f}}^{\prime}-\sigma_{\mathrm{cs}}\right)\right. \\
& \left.+E_{\mathrm{c}}\left(\frac{R_{I}}{R_{0}}-y \frac{R_{B}}{R_{0}}\right) f_{\mathrm{p} 1}+E_{\mathrm{c}}\left(\frac{R_{B}}{R_{0}}-y \frac{R_{A}}{R_{0}}\right) f_{\mathrm{p} 2}\right]
\end{aligned}
$$

in which $R_{A}, R_{B}$ and $R_{I}$ represent the axial rigidity, the stiffness associated with the first moment of area and the flexural rigidity, respectively, calculated at time $t_{0}$ under uncracked conditions, while the remaining notation has already been defined in the previous section. The derivation of Equation $8 \mathrm{a}$ has been carried out by considering a cross-sectional analysis formulated with an arbitrary reference axis, such as the one outlined in Figure 4, and by enforcing the equilibrium, compatibility and constitutive equations at the cross-section as, for example, described in Gilbert and Ranzi (2011). In this case, $M_{\text {cr }}$ has been calculated as the moment at which the tensile stress in the bottom fibre of the concrete equals the stress level required for the concrete to crack and, in the adopted notation, this stress level is denoted as $\left(f_{\mathrm{ct}, \mathrm{f}}^{\prime}-\sigma_{\mathrm{cs}}\right)$ (with $\sigma_{\mathrm{cs}}$ defined in Equation 9a). The values for $R_{A}, R_{B}$ and $R_{I}$ are determined as follows

8b. $\quad R_{A}=A_{\mathrm{c}} E_{\mathrm{c}}+A_{\mathrm{ss}} E_{\mathrm{ss}}+\sum A_{\mathrm{s}} E_{\mathrm{s}}+\sum A_{\mathrm{p}} E_{\mathrm{p}}$

8c. $\quad R_{B}=B_{\mathrm{c}} E_{\mathrm{c}}+B_{\mathrm{ss}} E_{\mathrm{ss}}+\sum y_{\mathrm{s}} A_{\mathrm{s}} E_{\mathrm{s}}+\sum y_{\mathrm{p}} A_{\mathrm{p}} E_{\mathrm{p}}$ 8d. $\quad R_{I}=I_{\mathrm{c}} E_{\mathrm{c}}+I_{\mathrm{ss}} E_{\mathrm{ss}}+\sum y_{\mathrm{s}}^{2} A_{\mathrm{s}} E_{\mathrm{s}}+\sum y_{\mathrm{p}}^{2} A_{\mathrm{p}} E_{\mathrm{p}}$

8e. $\quad R_{0}=R_{I} R_{A}-R_{B}^{2}$

where subscripts 'c', 'ss', 's' and 'p' depict the concrete component, the profiled steel sheeting, the steel reinforcement and the prestressing steel, respectively; $E$ is the elastic modulus; $A$, $B$ and $I$ represent the geometric area, first moment of area and second moment of area, respectively; the summations are assumed to be applied to all steel reinforcing bars and prestressing strands; and $y$ defines the positioning of the reinforcing bars or prestressing strands on the vertical axis. The expressions included in Equations 8b-8e are calculated based on an arbitrary reference system, as shown in Figure 4. The use of an arbitrary reference system enables the calculation of the geometric properties of the materials forming the crosssection to be performed only once and to be applicable for the evaluation of the cross-sectional rigidities required in the instantaneous, creep and shrinkage deflection predictions, as outlined in the following (e.g. the uncracked and the cracked second moments of area to be used for the deflection calculations are presented in Equations 11a and 11b). The term $\sigma_{\mathrm{cs}}$ introduced in Equation 8a can be evaluated from

9a.

$$
\begin{aligned}
\sigma_{\mathrm{cs}}= & \frac{E_{\mathrm{ef}, \mathrm{cs}}}{R_{I, \mathrm{cs}} R_{A, \mathrm{cs}}-R_{B, \mathrm{cs}}^{2}}\left[\left(R_{I, \mathrm{cs}}-y R_{B, \mathrm{cs}}\right) f_{\mathrm{cs} 1}\right. \\
& \left.+\left(R_{B, \mathrm{cs}}-y R_{A, \mathrm{cs}}\right) f_{\mathrm{cs} 2}\right]-E_{\mathrm{ef}, \mathrm{cs}}\left(\varepsilon_{\mathrm{r}, \mathrm{cs}}-y \kappa_{\mathrm{cs}}\right)
\end{aligned}
$$

and

9b. $\quad\left[\begin{array}{c}f_{\mathrm{cs} 1} \\ f_{\mathrm{cs} 2}\end{array}\right]=E_{\mathrm{ef}, \mathrm{cs}}\left[\begin{array}{c}A_{\mathrm{c}} \varepsilon_{\mathrm{r}, \mathrm{cs}}-B_{\mathrm{c}} \kappa_{\mathrm{r}, \mathrm{cs}} \\ -B_{\mathrm{c}} \varepsilon_{\mathrm{r}, \mathrm{cs}}+I_{\mathrm{c}} \kappa_{\mathrm{r}, \mathrm{cs}}\end{array}\right]$

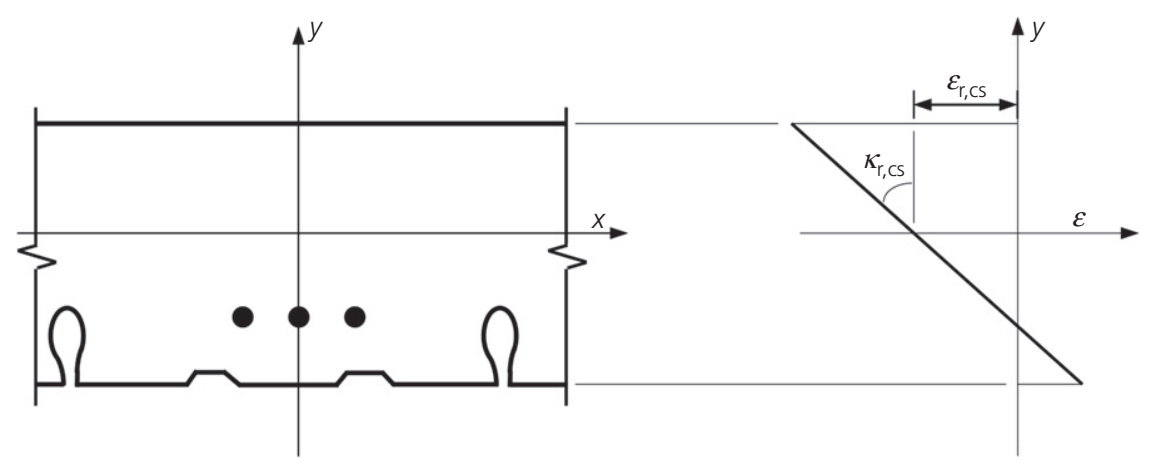

(a)

(b)

Figure 4. Composite cross-section: (a) arbitrary reference system; (b) arbitrary shrinkage gradient 
where the cross-sectional rigidities used to calculate the shrinkage effects have been referred to as $R_{A, \mathrm{cs}}, R_{B, \mathrm{cs}}$ and $R_{I, \mathrm{cs}}$ because they are evaluated using the effective modulus $E_{\text {ef,cs }}$ (i.e. determined by replacing the elastic modulus of the concrete $E_{\mathrm{c}}$ with $E_{\text {ef,cs }}$ in Equations 8b-8e), the shrinkage gradient is represented by the shrinkage strain at the level of the arbitrary reference axis $\varepsilon_{\mathrm{cs} . \mathrm{r}}$ and the shrinkage curvature $\kappa_{\mathrm{cs} . \mathrm{r}}$ (Figure 4(b)).

In Equation 8, the prestressing contribution is included by means of the terms $f_{\mathrm{p} 1}$ and $f_{\mathrm{p} 2}$ that are calculated as follows

$10 a$.

$$
f_{\mathrm{p} 1}=\sum A_{\mathrm{p}} E_{\mathrm{p}} \varepsilon_{\mathrm{p}, \text { init }}\left(1-\phi_{\mathrm{p}}\right)
$$

10b. $f_{\mathrm{p} 2}=-\sum y_{\mathrm{p}} A_{\mathrm{p}} E_{\mathrm{p}} \varepsilon_{\mathrm{p}, \text { init }}\left(1-\phi_{\mathrm{p}}\right)$
The deflection component produced by shrinkage can be obtained for a prismatic simply-supported member as follows

13. $\delta_{\mathrm{cs}}=\frac{\kappa_{\mathrm{cs}} L^{2}}{8}$

where the shrinkage curvature $\kappa_{\mathrm{cs}}$ is determined based on the shrinkage effects evaluated for the uncracked and cracked scenarios (Equation 5). For segments with adjacent spans or overhangs, the mid-span deflection due to shrinkage can be obtained using the approximation of Equation 7.

The shrinkage curvatures associated with the uncracked and cracked conditions, namely $\kappa_{\mathrm{cs}, \text { uncr }}$ and $\kappa_{\mathrm{cs}, \mathrm{cr}}$, are determined for a particular cross-section based on the following expressions

$\kappa_{\mathrm{cs}, \mathrm{uncr}}=\left[\begin{array}{ll}\frac{R_{B, \mathrm{cs}, \mathrm{uncr}}}{R_{0, \mathrm{cs}, \mathrm{uncr}}} & \frac{R_{A, \mathrm{cs}, \mathrm{uncr}}}{R_{0, \mathrm{cs}, \mathrm{uncr}}}\end{array}\right] E_{\mathrm{ef}, \mathrm{cs}}\left[\begin{array}{c}A_{\mathrm{c}, \mathrm{uncr}} \varepsilon_{\mathrm{r}, \mathrm{cs}}-B_{\mathrm{c}, \mathrm{uncr}} \kappa_{\mathrm{r}, \mathrm{cs}} \\ -B_{\mathrm{c}, \mathrm{uncr}} \varepsilon_{\mathrm{r}, \mathrm{cs}}+I_{\mathrm{c}, \mathrm{uncr}} \kappa_{\mathrm{r}, \mathrm{cs}}\end{array}\right]$

$14 \mathrm{~b}$.

$$
\kappa_{\mathrm{cs}, \mathrm{cr}}=\left[\begin{array}{ll}
\frac{R_{B, \mathrm{cs}, \mathrm{cr}}}{R_{0, \mathrm{cs}, \mathrm{cr}}} & R_{A, \mathrm{cs}, \mathrm{cr}} \\
R_{0, \mathrm{cs}, \mathrm{cr}}
\end{array}\right] E_{\mathrm{ef}, \mathrm{cs}}\left[\begin{array}{c}
A_{\mathrm{c}, \mathrm{cr}} \varepsilon_{\mathrm{r}, \mathrm{cs}}-B_{\mathrm{c}, \mathrm{cr}} \kappa_{\mathrm{r}, \mathrm{cs}} \\
-B_{\mathrm{c}, \mathrm{cr}} \varepsilon_{\mathrm{r}, \mathrm{cs}}+I_{\mathrm{c}, \mathrm{cr}} \kappa_{\mathrm{r}, \mathrm{cs}}
\end{array}\right]
$$
the initial prestressing (strain value calculated by dividing prestressing force applied to a strand by its axial rigidity) and $\phi_{\mathrm{p}}$ is the creep coefficient for the prestressing steel.

In the determination of the effective second moment of area (Equation 2), the uncracked and cracked second moments of area of the composite cross-section, namely $I_{\text {uncr }}$ and $I_{\mathrm{cr}}$, can be obtained from the cross-sectional rigidities calculated with respect to an arbitrary reference system (Figure 4(a)) using the following expressions

11a. $\quad I_{\text {uncr }}=\frac{R_{I} R_{A}-R_{B}^{2}}{R_{A} E_{\mathrm{c}}}$

11b. $\quad I_{\mathrm{cr}}=\frac{R_{I, \mathrm{cr}} R_{A, \mathrm{cr}}-R_{B, \mathrm{cr}}^{2}}{R_{A, \mathrm{cr}} E_{\mathrm{c}}}$

where the stiffness properties associated with the cracked section have been denoted as $R_{A, \mathrm{cr}}, R_{B, \mathrm{cr}}$ and $R_{I, \mathrm{cr}}$, and are determined using Equations $8 \mathrm{~b}-8 \mathrm{e}$ considering only the cracked section for the concrete component.

The creep deflection component $\delta_{\mathrm{cc}}$ is obtained multiplying the sustained part of the instantaneous deflection by the creep multiplier $\alpha_{\mathrm{cc}}$ as follows (Equation 4)

12. $\delta_{\mathrm{cc}}=\delta_{0, \text { sus }} \alpha_{\mathrm{cc}}=\left(\frac{q_{0, \text { sus }}}{q_{0}} \delta_{0}\right) \alpha_{\mathrm{cc}}$ where the subscripts 'uncr' and 'cr' denote the uncracked and cracked cross-section, respectively.

\section{Validation of the design model}

The design model presented in the previous sections is validated in the following considering experimental measurements and material properties reported in the literature for composite slabs and post-tensioned composite slabs. Key features of the experiments considered in this section are summarised in Table 1.

The long-term tests on composite slabs reported in Gholamhoseini (2014) and Gholamhoseini et al. (2014) include ten specimens with total length of $3300 \mathrm{~mm}$ and an internal span between supports of $3100 \mathrm{~mm}$. The samples were cast on two different sheeting profiles, KF40 and KF70 (Fielders Australia, 2008) with thickness of $0.75 \mathrm{~mm}$, with slab width of $1200 \mathrm{~mm}$ and slab thickness of $150 \mathrm{~mm}$. Both profiles are trapezoidal with trough heights of about $40 \mathrm{~mm}$ and $70 \mathrm{~mm}$ for the KF40 and KF70 profiles, respectively. The experimental programme was subdivided in two series, namely, a first series based on the KF70 profile followed by a series prepared with KF40 steel sheeting. The concrete properties adopted in the calculations are those reported in Gholamhoseini (2014) and Gholamhoseini et al. (2014). The shrinkage measurements were recorded from concrete prisms with dimensions $75 \mathrm{~mm} \times 75 \mathrm{~mm} \times 275 \mathrm{~mm}$ and have been 
Table 1. Summary of specimens used for the model validation

\begin{tabular}{|c|c|c|c|c|c|}
\hline Specimen ID & $\begin{array}{l}\text { Steel profiled } \\
\text { sheeting }\end{array}$ & $\begin{array}{l}\text { Total (internal) span: } \\
\text { mm }\end{array}$ & $\begin{array}{l}\text { Slab width: } \\
\mathrm{mm}\end{array}$ & $\begin{array}{l}\text { Slab thickness: } \\
\mathrm{mm}\end{array}$ & $\begin{array}{l}\text { External sustained load: kPa } \\
\text { (excluding self-weight) }\end{array}$ \\
\hline $\begin{array}{l}1 \mathrm{LT}-70-0^{\mathrm{a}} \\
2 \mathrm{LT}-70-3^{\mathrm{a}} \\
3 \mathrm{LT}-70-3^{\mathrm{a}} \\
4 \mathrm{LT}-70-6^{\mathrm{a}} \\
5 \mathrm{LT}-70-8^{\mathrm{a}}\end{array}$ & $\mathrm{KF} 7 \mathrm{O}^{\mathrm{b}}$ & $3300(3100)$ & 1200 & 150 & $\begin{array}{l}\text { None } \\
3 \cdot 4(\text { from } 64 \mathrm{~d}) \\
3 \cdot 4(\text { from } 64 \mathrm{~d}) \\
6 \text { (from } 64 \mathrm{~d}) \\
6 \cdot 1 \text { (between } 64 \text { and } 197 \mathrm{~d}) \text {, } \\
\quad 7.9 \text { (from } 197 \mathrm{~d} \text { ) }\end{array}$ \\
\hline $\begin{array}{l}6 L T-40-0^{a} \\
7 L T-40-3^{a} \\
8 L T-40-3^{a} \\
9 L T-40-6^{a} \\
10 L T-40-6^{a}\end{array}$ & $\mathrm{KF} 40^{\mathrm{b}}$ & $3300(3100)$ & 1200 & 150 & $\begin{array}{l}\text { None } \\
3 \cdot 4(\text { from } 28 d \text { d) } \\
3 \cdot 4(\text { from } 28 d \text { ) } \\
6 \cdot 4(\text { from } 28 d \text { ) } \\
6 \cdot 4 \text { (from } 28 d \text { d) }\end{array}$ \\
\hline $\begin{array}{l}\mathrm{CS}_{1}{ }^{c} \\
\mathrm{CS} 2^{\mathrm{c}}\end{array}$ & Condeck HP & $3300(3000)$ & 900 & 180 & None \\
\hline $\begin{array}{l}\mathrm{CK} 2^{\mathrm{e}} \\
\mathrm{CK} 5^{\mathrm{e}}\end{array}$ & Condeck $\mathrm{HP}^{\mathrm{g}}$ & $\begin{array}{l}7200(6000) \\
8650(7450)\end{array}$ & 900 & $\begin{array}{l}180 \\
225\end{array}$ & None \\
\hline$C K^{f}$ & Condeck HPg & $7200(6000)$ & 900 & 180 & None \\
\hline
\end{tabular}

${ }^{a}$ From references Gholamhoseini (2014) and Gholamhoseini et al. (2014)

bProfiled sheeting: $0.75 \mathrm{~mm} \mathrm{KF40} \mathrm{and} \mathrm{KF70} \mathrm{(Fielders} \mathrm{Australia,} \mathrm{2008)}$

'From reference Al-Deen et al. (2015)

dProfiled sheeting: 0.75 mm Stramit Condeck HP profiled sheeting (Stramit, 2012)

'eFrom reference Ranzi et al. (2012)

fFrom reference Ranzi et al. (2013b)

'Profiled sheeting: $1.0 \mathrm{~mm}$ Stramit Condeck HP profiled sheeting (Stramit, 2012)

modified in the numerical calculations to account for the differences in hypothetical thicknesses of the prisms and the samples.

The KF70 samples were placed in their simply-supported configuration at $7 \mathrm{~d}$ from casting. One specimen was maintained unloaded for the entire duration of the long-term test until $247 \mathrm{~d}$ from casting, therefore being subjected to creep due to its self-weight and to shrinkage effects. This sample was referred to as 1LT-70-0 with the specimen notation defined as: first digit refers to the sample number, 'LT' denotes the longterm test, followed by ' 70 ' and ' 0 ' that depict the profile code, i.e. KF70, and the approximate external sustained load applied to the sample, namely, 0 for no external load. The other two samples considered in the following are denoted 2LT-70-3 and 3LT-70-3, and differ from specimen 1LT-70-0 because they were loaded with a sustained load of $3.4 \mathrm{kPa}$ (i.e. $3.4 \mathrm{kPa} \times 1.2 \mathrm{~m}=4.08 \mathrm{kN} / \mathrm{m})$ at $64 \mathrm{~d}$ from casting. The same loading instant was specified for sample 4LT-70-6, which was subjected to an external sustained action equivalent to $6 \mathrm{kPa}$ (i.e. $6 \mathrm{kPa} \times 1.2 \mathrm{~m}=7.2 \mathrm{kN} / \mathrm{m}$ ). Two loading steps related to sustained loads of $6 \cdot 1 \mathrm{kPa}$ (i.e. $6 \cdot 1 \mathrm{kPa} \times 1.2 \mathrm{~m}=7.32 \mathrm{kN} / \mathrm{m}$ ) and $7.9 \mathrm{kPa}$ (i.e. $7.9 \mathrm{kPa} \times 1.2 \mathrm{~m}=9.48 \mathrm{kN} / \mathrm{m}$ ) were specified for specimen 5LT-70-8 at 64 and $197 \mathrm{~d}$ from casting, respectively. Figures 5(a)-5(d) show good agreement between the measured results and those calculated with the shrinkage gradient, whereas the use of the uniform shrinkage profile underestimates the deflections. In the latter case, the uniform shrinkage values have been determined adopting a hypothetical thickness equal to twice the depth of the composite slab (also carried out in all comparisons presented in this section) to reflect the current practice that makes use of the constant shrinkage profile.

Similar loading arrangements were specified for the KF40 samples with the only difference being that the external sustained loads were applied at $28 \mathrm{~d}$ from casting and maintained for $223 \mathrm{~d}$.

One specimen, 6LT-40-0, was kept unloaded for the entirety of the long-term tests. Companion samples 7LT-40-3 and 8LT-40-3 were subjected to an external action of $3.4 \mathrm{kPa}$ (i.e. $3.4 \mathrm{kPa} \times 1.2 \mathrm{~m}=4.08 \mathrm{kN} / \mathrm{m}$ ), while a sustained loading of $6.4 \mathrm{kPa}$ (i.e. $6.4 \mathrm{kPa} \times 1.2 \mathrm{~m}=7.68 \mathrm{kN} / \mathrm{m}$ ) was applied to specimens 9LT-40-6 and 10LT-40-6. Also in this case, good agreement is observed in Figures 6(a)-6(c) between the measured data and values evaluated accounting for the presence of the shrinkage gradient. Smaller deflections are obtained with uniform shrinkage leading to underestimation of the test displacements.

The test results presented in Figures 5 and 6 provide a good representation of the range of variability that is usually encountered in long-term (service) experiments and that can reach variations of even $20-30 \%$. For example, the long-term tests depicted in Figures 6(b) and 6(c) are subjected to different levels of sustained loads (with a difference in the load level of 


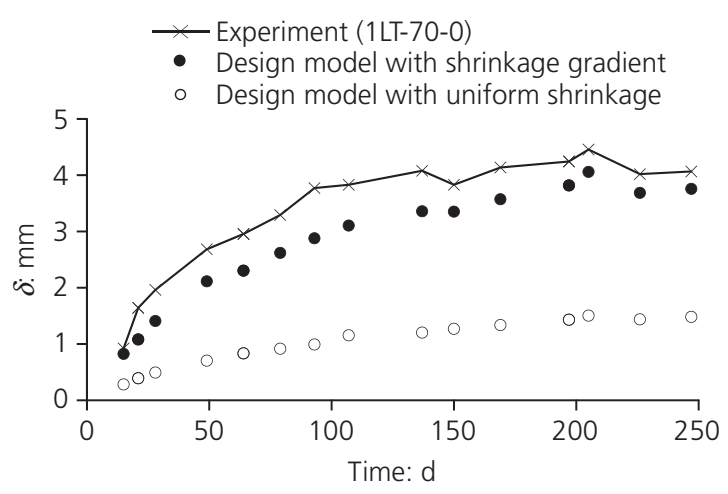

(a)

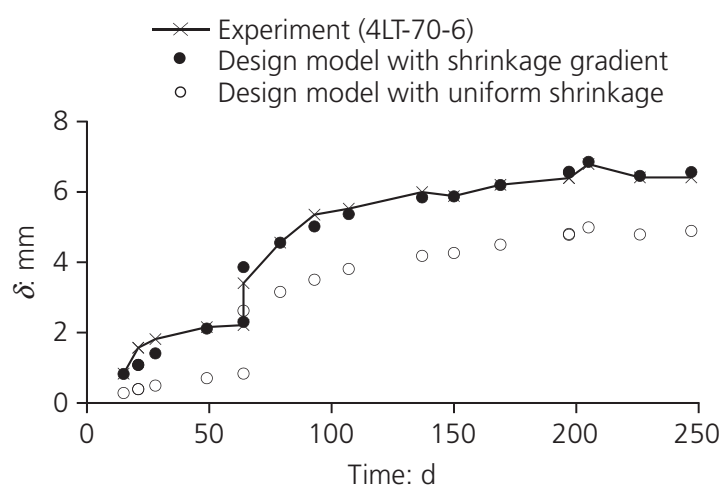

(c)

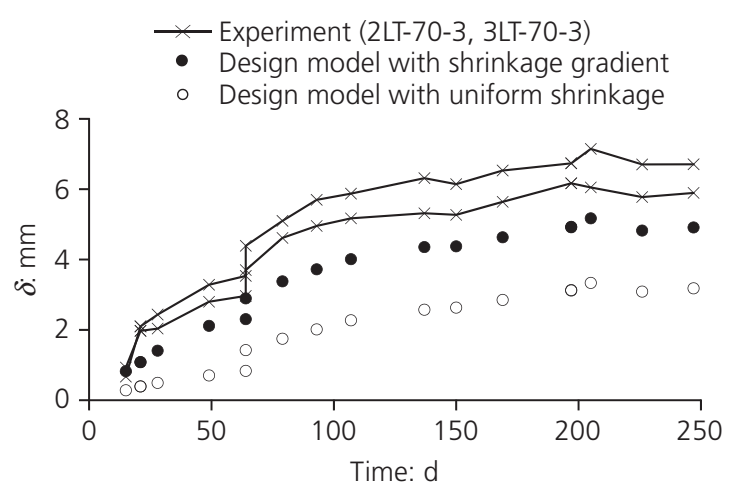

(b)

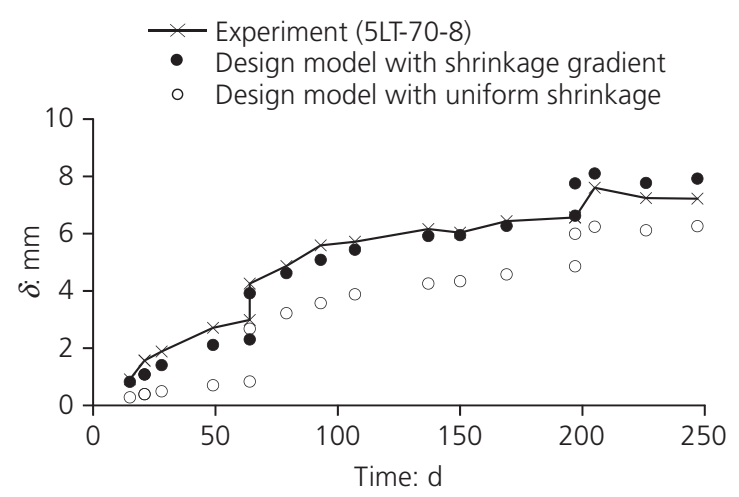

(d)

Figure 5. Comparisons between experimental measurements and calculated values: (a) sample 1LT-70-0; (b) samples 2LT-70-3 and 3LT-70-3; (c) sample 4LT-70-6; (d) sample 5LT-70-8

about $3 \mathrm{kPa}$ applied over the slab surface) and, despite this, exhibited very similar deflections in the tests.

Experimental work comparing the response of composite steel-concrete and reinforced concrete slabs were presented in Al-Deen et al. (2015). The two composite slab samples reported in this reference are considered in the following and consist of two composite slabs, referred to as CS1 and CS2, cast on $0.75 \mathrm{~mm}$ Stramit Condeck HP profiled sheeting (Stramit, 2012). The specimens had total length of $3300 \mathrm{~mm}$ with an internal span between roller supports of $3000 \mathrm{~mm}$. Sample CS1 was prepared with no reinforcing bars, whereas five N16 reinforcing bars were used for CS2 to provide an amount of top reinforcement equivalent to the steel area of the profiled sheeting. Figures 7(a) and 7(b) highlight the good match between the calculated and recorded values when considering the presence of shrinkage gradient. The numerical predictions based on the use of the uniform shrinkage underestimate the overall deflections for both samples.

The specimens reported in Ranzi et al. (2012) and Ranzi et al. (2013b) have been considered for the validation of the design approach when dealing with post-tensioned composite slabs. For these cases, the slip observed over time in the experiments was negligible. In particular, two post-tensioned specimens out of the six samples described in Ranzi et al. (2012) were subjected to shrinkage affects and to creep of their self-weight before taking them to failure at about $120 \mathrm{~d}$ (for sample CK2) and $40 \mathrm{~d}$ from casting (for sample CK5). Over this period long-term measurements were recorded. These specimens were cast on Stramit Condeck HP steel deck (Stramit, 2012) and differed in their thicknesses $(180 \mathrm{~mm}$ for CK2 and $225 \mathrm{~mm}$ for CK5), total lengths $(7200 \mathrm{~mm}$ for CK2 and $8650 \mathrm{~mm}$ for CK5) and internal spans between rollers supports $(6000 \mathrm{~mm}$ for CK2 and $7450 \mathrm{~mm}$ for CK5). Three and four prestressing strands were specified for samples CK2 and CK5, respectively. Good agreement was noted between the measured data and the predictions calculated with the shrinkage gradient as depicted in Figures 8(a) and 8(b), whereas the use of a uniform shrinkage distribution produced smaller values. Another sample (referred to as CK) with identical dimensions and static configuration of sample CK2 was exposed to a long-term test for a duration of nearly $250 \mathrm{~d}$, as reported in Ranzi et al. (2013b). Also in this case the deflections obtained with the shrinkage gradient are close to the experimental measurements, whereas the vertical displacements determined with the uniform shrinkage underestimate the deformations as shown in Figure 9. 


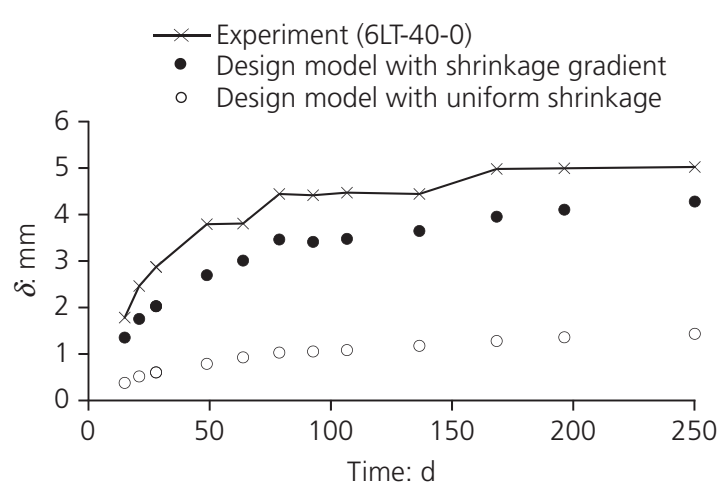

(a)

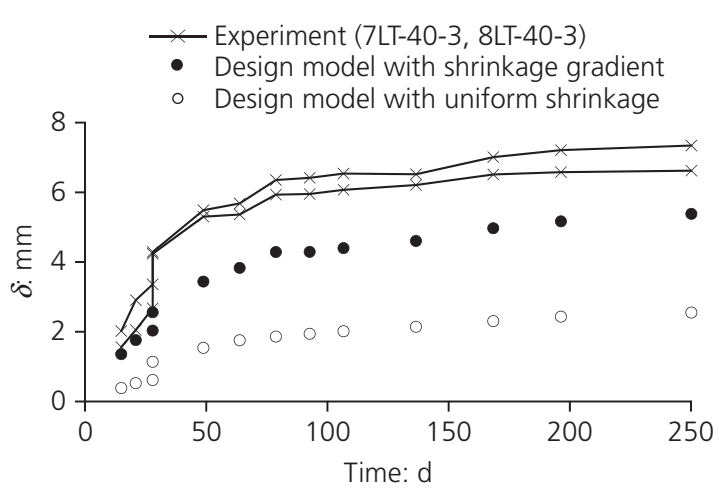

(b)

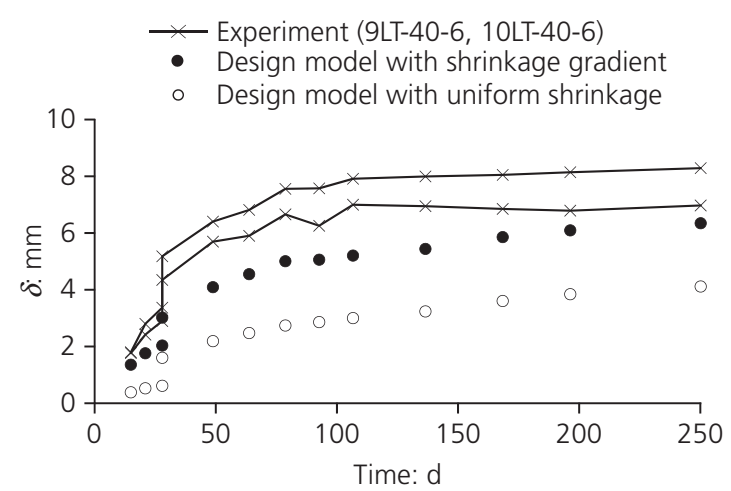

(c)

Figure 6. Comparisons between experimental measurements and calculated values: (a) sample 6LT-40-0; (b) samples 7LT-40-3 and 8LT-40-3; (c) samples 9LT-40-6 and 10LT-40-6

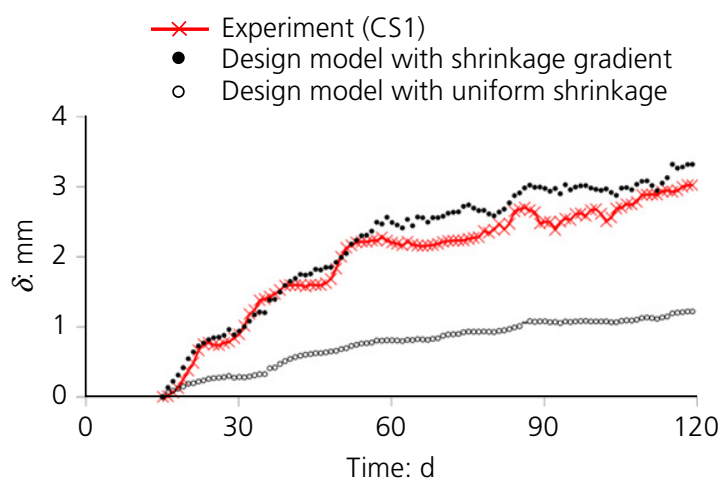

(a)

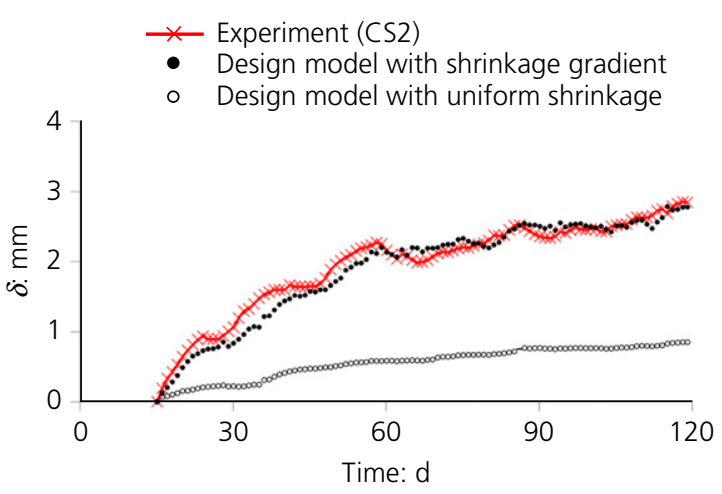

(b)

Figure 7. Comparisons between experimental measurements and calculated values: (a) sample CS1; (b) sample CS2

\section{Conclusions}

The final remarks of the paper are summarised and listed below.

A design model for the service design of composite steel-concrete floors was presented. The approach is applicable to composite slabs and post-tensioned composite slabs commonly adopted in steel and concrete structures, respectively.

- The particularity of the proposed methodology relies on its ability to account for the occurrence of shrinkage gradients through the composite slab thickness that occur due to the inability of the concrete to dry from the underside of the slab because of the presence of the steel sheeting. 


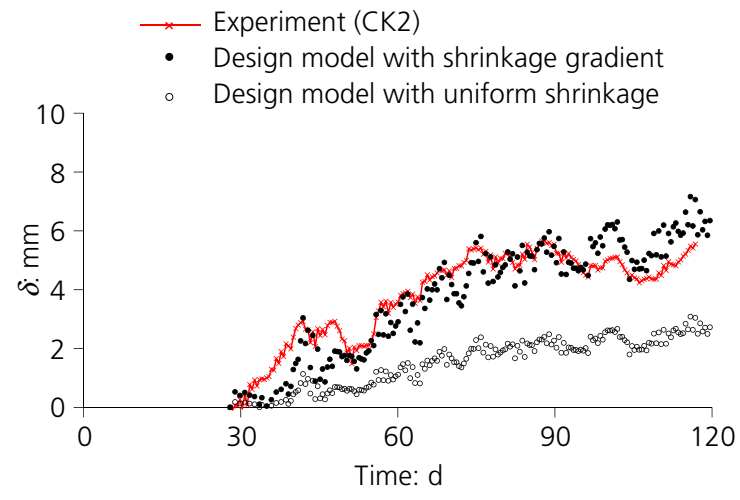

(a)

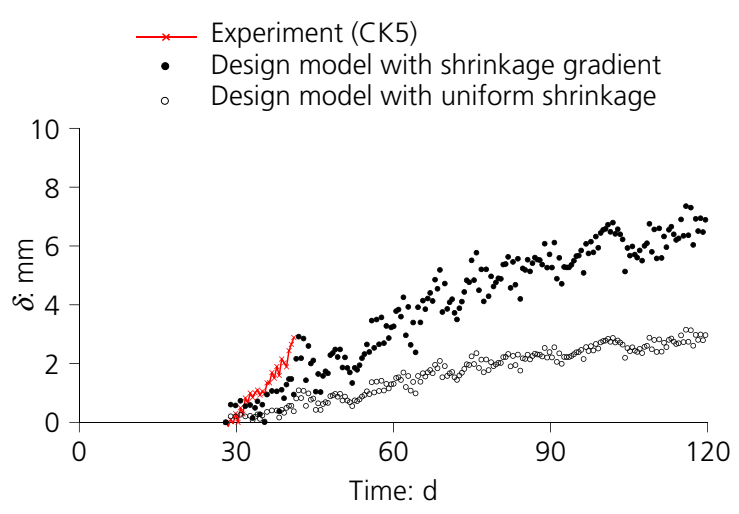

(b)

Figure 8. Comparisons between experimental measurements and calculated values: (a) sample CK2; (b) sample CK5

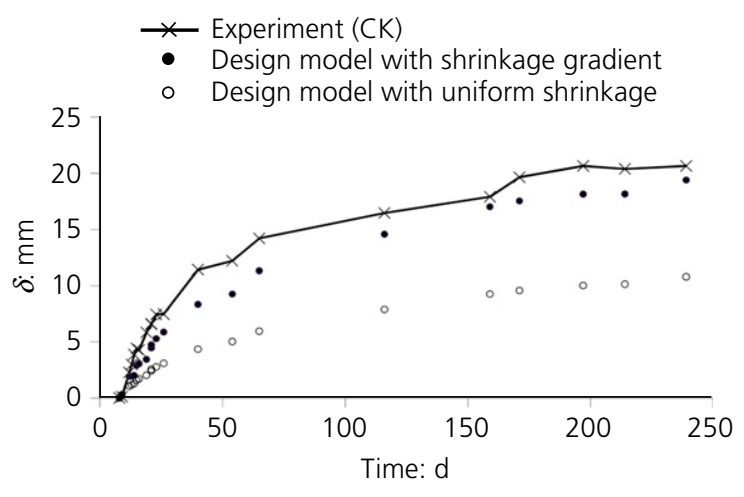

Figure 9. Comparisons between experimental measurements and calculated values for sample CK

Expressions suitable for routine design were presented after introducing the key features of the design model.

- The proposed design equations were used to predict deflection measurements reported in the literature and recorded during long-term tests carried out on composite slabs and post-tensioned composite slabs. The numerical predictions obtained using the design equations considering the shrinkage gradient showed good agreement with the final experimental measurements, with average final differences in the order of $-12 \%$. The use of uniform shrinkage produced larger variations where the numerical results underestimated the measured deflections, with average final differences in the order of $-54 \%$.

\section{Acknowledgements}

The contribution of the work reported in this paper was supported by the Australian Research Council through its Future Fellowship scheme (FT140100130). Support from the University of Sydney (Materials \& Structures Research Cluster) is also gratefully acknowledged.

\section{REFERENCES}

Al-Deen S and Ranzi G (2015) Effects of non-uniform shrinkage on the long-term behaviour of composite steel-concrete slabs. International Journal of Steel Structures 15(2): 415-432.

Al-Deen S, Ranzi G and Vrcelj Z (2011) Full-scale long-term and ultimate experiments of simply-supported composite beams with steel deck. Journal of Constructional Steel Research 67(10): 1658-1676.

Al-Deen S, Ranzi G and Uy B (2015) Non-uniform shrinkage in simply-supported composite steel-concrete slabs. Steel and Composite Structures 18(2): 375-394.

Bradford MA (2010) Generic modelling of composite steel-concrete slabs subjected to shrinkage, creep and initial thermal strains including partial interaction. Engineering Structures 32(5): 1459-1465.

BSI (2002) BS EN 1990: Eurocode 0. Basis of structural design. BSI, London, UK.

BSI (2004) BS EN 1992-1-1: Eurocode 2. Design of concrete structures. Part 1-1. General rules and rules for buildings. BSI, London, UK.

BSI (2005) BS EN 1994-1-1: Eurocode 4. Design of composite steel and concrete structures. Part 1.1. General rules and rules for buildings. BSI, London, UK.

Fielders Australia (2008) Specifying Fielders - Kingflor - Composite Steel Formwork System Design Manual. Fielders Australia Pty Ltd, Marleston, Australia.

Gholamhoseini A (2014) Time-Dependent Behaviour of Composite Concrete Slabs. PhD thesis, The University of New South Wales, Sydney, NSW, Australia.

Gholamhoseini A, Gilbert RI, Bradford MA and Chang ZT (2014) Time-dependent deflection of composite concrete slabs. ACI Structural Journal 111(4): 765-776.

Gilbert RI and Ranzi G (2011) Time-Dependent Behaviour of Concrete Structures. Spon Press, London, UK.

Gilbert RI, Bradford MA, Gholamhoseini A and Chang ZT (2012) Effects of shrinkage on the long-term stresses and deformations of composite concrete slabs. Engineering Structures 40: 9-19, https://doi.org/10.1016/j.engstruct.2012.02.016.

Gilbert RI, Mickleborough NC and Ranzi G (2017) Design of Prestressed Concrete to Eurocode 2. CRC Press, Boca Raton, FL, USA.

Ranzi G and Gilbert RI (2015) Structural Analysis: Principles, Methods and Modelling. CRC Press, Boca Raton, FL, USA.

Ranzi G and Vrcelj Z (2009) Closed form solutions for the long-term analysis of composite steel-concrete members subjected to non-uniform shrinkage distributions. Proceedings of the 5th International Conference on Advances in Steel Structures (ICASS'09), Hong Kong, China (Chan SL (ed.)). The 
Hong Kong Institute of Steel Construction, Hong Kong, pp. 552-559.

Ranzi G, Ostinelli A and Uy B (2012) An experimental study on the shrinkage and ultimate behaviour of post-tensioned composite slabs. In Proceedings of the 22nd Australasian Conference on the Mechanics of Structures and Materials (ACMSM22), Sydney, Australia: From Materials to Structures: Advancement through Innovation (Samali B, Attard MM and Song C (eds)), pp. 339-344. CRC Press, Boca Raton, FL, USA.

Ranzi G, Leoni G and Zandonini R (2013a) State of the art on the time-dependent behaviour of composite steel-concrete structures. Journal of Constructional Steel Research 80: 252-263, https://doi.org/10.1016/j.jcsr.2012.08.005.

Ranzi G, Al-Deen S, Ambrogi L and Uy B (2013b) Long-term behaviour of simply-supported post-tensioned composite slabs. Journal of Constructional Steel Research 88: 172-180, https://doi.org/10.1016/ j.jcsr.2013.05.010.
SA (Standards Australia) (2002) AS/NZS 1170.0-2002:

Australian/New Zealand Standard for structural design actions - part 0: general principles. Draft version. Standards Australia, Sydney, Australia.

SA (2009) AS 3600-2009: Australian Standard for concrete structures. Standards Australia, Sydney, Australia.

SA (2017) AS 2327-2017: Australian Standard for composite structures. Draft version. Standards Australia, Sydney, Australia.

Shayan S, Al-Deen S, Ranzi G and Vrcelj Z (2010) Long-term behaviour of composite concrete slabs: an experimental study. In Proceedings of the 4th International Conference on Steel \& Composite Structures (ICSCS'10), Sydney, Australia (Uy B, Tao Z, Mashiri F et al. (eds)), Research Publishing, Singapore.

Stramit (2012) Stramit Condeck HP, Composite Slab System, Product Technical Manual. Stramit Corporation Property Limited, Queensland, Australia.

\section{How can you contribute?}

To discuss this paper, please email up to 500 words to the editor at journals@ice.org.uk. Your contribution will be forwarded to the author(s) for a reply and, if considered appropriate by the editorial board, it will be published as discussion in a future issue of the journal.

Proceedings journals rely entirely on contributions from the civil engineering profession (and allied disciplines). Information about how to submit your paper online is available at www.icevirtuallibrary.com/page/authors, where you will also find detailed author guidelines. 